\title{
Alkali production in the mouth and its relationship with certain patient's characteristics
}

\author{
Valeria Veiga GORDAN¹, Deborah Landry McEDWARD', Marc Edward OTTENGA', Cynthia Wilson GARVAN², Pearl \\ Ann HARRIS
}

1- College of Dentistry, Department of Restorative Dental Sciences at University of Florida, Gainesville, Florida, USA.
2- College of Nursing, University of Florida, Gainesville, Florida, USA.

Corresponding address: Valeria V. Gordan - University of Florida, College of Dentistry - P.O.Box 100415 - Gainesville - FL - $32610-0415$ - Phone: 352 273 5846 - Fax: 3522737970 - e-mail: vgordan@dental.ufl.edu

Submitted: June 10, 2014 - Modification: August 18, 2014 - Accepted: August 19, 2014

\section{ABSTRACT}

\begin{abstract}
bjectives: To assess the relationships among alkali production, diet, oral health behaviors, and oral hygiene. Methods: Data from 52 subjects including demographics, diet, and oral hygiene scores were analyzed against the level of arginine and urea enzymes in plaque and saliva samples. An oral habit survey was completed that included: use of tobacco (TB), alcohol (AH), sugary drinks (SD), and diet. Alkali production through arginine deiminase (ADS) and urease activities were measured in smooth-surface supragingival dental plaque and un stimulated saliva samples from all subjects. ADS and urease activities were measured by quantification of the ammonia generated from the incubation of plaque or saliva samples. Spearman correlations were used to compute all associations. Results: Participants in the lowest SES (Socio-economic status) group had the habit of consuming sugary drinks the most and had the highest rate of tobacco use. Males consumed significantly more alcohol than females. No significant relationship was found between age or gender and alkali production. Higher rates of sugary drink consumption and tobacco use were significantly related to lower alkali production. Conclusion: The study showed a relationship between alkali production and oral hygiene, diet, and certain oral health behaviors. Poor oral hygiene was significantly associated with age, lower SES, tobacco use, and alcohol, and sugary drinks consumption. Clinical relevance: Certain oral health behaviors have an impact on oral hygiene and on alkali production; it is important to address these factors with patients as a strategy for caries control.
\end{abstract}

Keywords: Alkali. Oral hygiene. Smoking. Sugary drinks. Alcohol. Bacteria. Dental caries. Dental plaque. Saliva. Adult. Urease. Arginine.

\section{NTRODUCTION}

Dental caries constitutes an important health problem and it is the most prevalent chronic disease in humans. Over 96 percent of adults in the United States have experienced dental caries ${ }^{27}$. The identification of factors that may contribute to the development of dental caries may significantly reduce the gravity and extent of the disease.

Dental caries originates from prolonged plaque acidification resulting from the metabolic activity of cariogenic microbiota which leads to demineralization of the tooth. Some microbiological risk factors for dental caries have been identified ${ }^{11,14,28}$ which originated the concept that an individual's change from caries-free to caries-active status may be related to a reduced potential to generate alkali in the plaque, in addition to resulting in an increased acidogenic environment. The two major mechanisms of alkali production in the oral environment are through the urease and arginine deiminase pathways $s^{6,13}$ in which urea is hydrolyzed by urease enzymes, present in a number of oral bacteria, to form ammonia. Ammonia can also be produced from arginine through the arginine deiminase system (ADS). A previous clinical study by Gordan, et al. ${ }^{11}$ (2010) showed a positive relationship between high levels of alkali production and caries resistance. Significantly higher ammonia production from arginine and urease in saliva and plaque samples 
was observed in caries-free subjects compared to caries-active subjects. Individuals who had active caries showed a reduced alkali-generating capacity of the bacteria colonizing the oral cavity.

An increased arginine rich diet may have an effect in the overall alkali production ${ }^{10,17}$. Understanding the factors that may affect alkali production and their relationship to other oral health behaviors is crucial when targeting caries prevention strategies. It is also important to assess the microbiota's environment, and since the lack of oral hygiene is directly responsible for plaque formation ${ }^{30}$, it becomes important to understand if certain oral health behaviors can also have an impact on oral hygiene. For example, previous studies have reported the detrimental effects of tobacco use in patients with periodontitis ${ }^{1}$, but studies have not widely explored the impact of tobacco use on alkali production. A preliminary study revealed a positive relationship between high levels of alkali production and caries resistance, the goal of the current paper was to build on data that has been published elsewhere ${ }^{11,21}$ specifically exploring the demographic characteristics of patients and certain patients' habits. Therefore, the current study aims to expand the understanding of other variables that may affect alkali production. The goal is to assess the relationships among alkali production, diet, oral health behaviors, and oral hygiene. We hypothesized that diet, certain oral health behaviors and oral hygiene would affect the alkali production.

\section{MATERI AL AND METHODS}

\section{Study design and subject population}

The study design was a cross-sectional study. Community members who responded to a posted advertisement and patients who presented for care in the dental clinics at the University of Florida were asked to participate in the study. All subjects were older than 18 years of age. A preliminary study was conducted and the results have been published elsewhere ${ }^{11,21}$. The current paper explored further the data that has been published elsewhere ${ }^{11,21}$, specifically exploring the demographic characteristics of patients and certain patients' habits.

The report on the current study includes data from fifty-two subjects who completed all the dietary food consumption forms described below. Participants met the inclusion/exclusion criteria and signed a consent form that was approved by the University's Institutional Review Board.

Oral hygiene was assessed using the O'Leary, Drake and Naylor Plaque Control Record method in which each tooth is divided into 4 surfaces. Therefore, the total percentage of plaque for each subject was obtained by dividing the number of tooth surfaces that presented plaque by the total number of surfaces present in the mouth ${ }^{24}$.

Dietary food consumption was reported as total food consumption, and average intake of arginine rich foods: nuts, dairy, protein, and vegetables/ grains (possible self-reported responses to each of the food items listed were: once/day, 2+ times/day, $1 /$ week, 1 /month, 1 /year, and never). Additionally, patients completed an oral habit survey indicating the average frequency and use of tobacco, sugary drinks, and alcohol.

The DMFT (decayed, missing, filled teeth) Index was used to access caries status. Dental caries was scored visually based on Ekstrand's visual criteria9. The DT and MFT values, respectively for caries-active and caries-experienced groups, were calculated separately using the DMFT index.

Patients who participated in the study completed a medical history form and a registration form that captured several variables to assess the subject's demographic profile, (i.e., Gender, Race, Ethnicity, Socio-economic status). The Coleman-Rainwater Social Class Hierarchy ${ }^{7}$ (Figure 1) was used to determine the socioeconomic status category for each subject.

\section{I nclusion criteria}

Subjects who 1) were 18 years of age or older; 2) had at least 20 teeth; 3) had no contraindications to regular dental treatment; and fell into one of the following groups: a) were caries-free (CF: cariesfree, total number of decayed, missing and filled

\begin{tabular}{|c|c|c|c|c|}
\hline Social Class & Sub Category & Income & Education & Occupation \\
\hline Lower & The Bottom & $0-14 \mathrm{~K}$ & & Unemployed or social services \\
\hline & Semi-poor & $14-18 \mathrm{~K}$ & High School & Labor and/or Service \\
\hline Middle & Working Class & $23-45 \mathrm{~K}$ & College & Upper "Blue Collar" \\
\hline & Middle Class & $30-60 \mathrm{~K}$ & Middle Management \\
\hline Upper & Upper-Middle & $114 \mathrm{~K}-250 \mathrm{~K}$ & College + Post-grad & Professional and Managerial \\
\hline & Lower-Upper & $251 \mathrm{~K}-1.672 \mathrm{M}$ & $\begin{array}{c}\text { Higher Degrees from "Good } \\
\text { Colleges" }\end{array}$ & Top Professionals \\
& Upper-Upper & $1.673 \mathrm{M}-$ & "Ivy League" Colleges / Inherited & \\
\hline
\end{tabular}

Figure 1- The Coleman-Rainwater Social Class Hierarchy 
teeth for each participant $[\mathrm{DMFT}]=0)$, b) had at least 4 teeth with active caries (CA: caries-active, number of decayed teeth [DT] for each participant $\geq 4$ ), or c) had experienced caries in at least 4 teeth and had remained caries-free for at least 12 months (CE: caries-experienced, number of missing and filled teeth [MFT] for each participant $\geq 4$ and number of decayed teeth $[D T]=0)$.

\section{Exclusion criteria}

Subjects who fit any one or more of the following criteria: 1 ) were younger than 18 years of age; 2 ) had less than 20 teeth; 3 ) had abnormally low flow rate of whole stimulated saliva (less than $0.5 \mathrm{ml} /$ min and less than $0.7 \mathrm{ml} / \mathrm{min}$, for women and men respectively) collected as part of the pre-screening process $^{22}$ or any systemic disease that can cause xerostomia; 4) were taking any medications that are known to cause xerostomia; 5) had been treated within the 3 months that preceded the study with either antibiotics, systemic or inhaled steroids; or with chlorhexidine; 6) were HIV positive; 7) had removable or fixed dental appliances (braces, cemented retainers, night-guard, removable partial dentures) which can lead to enhanced carbohydrate retention, more lactobacilli, and in turn to caries elevation ${ }^{26}$; 8 ) regularly used methamphetamine drugs; 9) had the habit of sucking on lemon; 10) had esophageal reflux disease; 11) had bulimia; 12) had a bleeding disorder or were on anticoagulant therapy; 13) had eaten in the 12 hours prior to sample collection; 14 ) had any oral hygiene procedures in the 12 hours prior to sample collection; or 15) who were unwilling or unable to provide informed consent and follow instructions.

\section{Sample collection and preparation}

Subjects were required to refrain from practicing oral hygiene and eating (including chewing gum or candy, or drinking fluids other than water) for 12 hours prior to sample collection. Whole unstimulated saliva samples and smooth surface plaque (pooled) were collected. Whole unstimulated saliva was collected by asking the patients to expectorate into a sterile plastic container. A minimum of $5 \mathrm{ml}$ of saliva was collected. Supragingival plaque was collected from all smooth dental surfaces of incisors and molars ${ }^{8}$ using sterile periodontal curettes (GR 3/46, curettes, Hu-Friedy Company, Chicago, IL, USA). Sampling included interproximal, labial/ buccal, and lingual surfaces of the teeth. Each portion of plaque scraped from surfaces of the teeth was immediately transferred to, and dispersed in, pre-weighed and sterile micro-centrifuge tubes

Table 1- Demographic distribution of the patients participating in the study $(n=52)$

\begin{tabular}{|c|c|c|c|}
\hline \multicolumn{2}{|c|}{ Characteristic } & \multicolumn{2}{|c|}{ Percent Distribution ( $\mathrm{n}$ ) or Mean (SD) } \\
\hline Age & & $30.7(10.9)$ & \\
\hline \multirow[t]{2}{*}{ Gender } & Male & $67 \%(35)$ & \\
\hline & Female & $33 \%(17)$ & \\
\hline \multirow[t]{3}{*}{ Race } & White & $83 \%(43)$ & \\
\hline & Black & $8 \%(4)$ & \\
\hline & Asian & $10 \%(5)$ & \\
\hline \multirow[t]{3}{*}{ SES } & 1- Lower & $13 \%(7)$ & \\
\hline & 2- Middle & $33 \%(17)$ & \\
\hline & 3- Upper & $54 \%(28)$ & \\
\hline \multicolumn{2}{|c|}{ Alcohol consumption } & & Mean ounces per day \\
\hline & Yes & $29 \%(15)$ & $1.8(1.1)$ \\
\hline & No & $71 \%(37)$ & \\
\hline \multicolumn{2}{|c|}{ Sugary drink consumption } & & Mean ounces per day \\
\hline & Yes & $44 \%(23)$ & $2.4(2.4)$ \\
\hline & No & $56 \%(29)$ & \\
\hline \multicolumn{2}{|c|}{ Tobacco use } & & $\begin{array}{l}\text { Mean number of cigarettes per day } \\
\text { (SD) }\end{array}$ \\
\hline & Yes & $23 \%(12)$ & $1.0(0.0)$ \\
\hline & No & $77 \%(40)$ & \\
\hline Nuts\# & & $201.1(70.0)$ & \\
\hline Veggie/C & & $563.2(888.0)$ & \\
\hline Dairy\# & & $344.5(418.0)$ & \\
\hline Protein\# & & $470.0(271.0)$ & \\
\hline Total Arg & iet\# & $1146.6(1871.0)$ & \\
\hline
\end{tabular}

*Dietary intake of arginine rich foods was available for 33 of the 52 participants

\# Mean number of occasions/year - SES=socio-economic status 
containing $10 \mathrm{mM} \mathrm{KPO}_{4}(\mathrm{pH}$ 7.0) buffer.

Dental plaque and saliva samples were dispersed by external sonification (Heat Systems, Ultrasonics, Farmingdale, NY, USA) for two cycles of $15 \mathrm{~s}$, with cooling on ice during the interval. Plaque samples were washed once in sterile $10 \mathrm{mM}$ Tris Maleate ( $\mathrm{pH} 7.0$ ) cold buffer and resuspended in $500 \mu$ of the same buffer in order to remove any background arginine and urea. ADS and urease activities in the samples were immediately measured using the standard biochemical assay described below.

\section{Biochemical measurement of ADS and urease}

ADS activity was measured by quantification of the ammonia generated from the incubation of resuspended dental plaque $(25 \mu \mathrm{l})$ and saliva samples $(5 \mu \mathrm{l})$ in a mixture containing $50 \mathrm{mM}$ Arginine- $\mathrm{HCl}$ (Sigma-Aldrich Canada, Oakville, Ontario, Canada) and $0.5 \mathrm{mM}$ Tris Maleate buffer
$(\mathrm{pH} 6.0)$ for 90 minutes at $37^{\circ} \mathrm{C}$. After the incubation period, the ammonia produced was measured with Nessler's reagent (Sigma-Aldrich, St. Louis, MO, USA) using ammonium sulfate as the standard. Ammonia can be readily detected, in very minute traces, by the addition of Nessler's solution, which gives a distinct yellow coloration in the presence of the least trace of ammonia. The sensitivity of this method as a spot test is about $0.3 \mu \mathrm{g} \mathrm{NH}$ in $2 \mu \mathrm{L}$. The solution is then submitted to a Nessler cylinder which is a simple type of colorimeter. Each sample was assayed in triplicate, and controls for background and interference were always included. Similarly, urease activity was measured by quantification of ammonia produced from $50 \mathrm{mM}$ of urea (Fisher Scientific, Pittsburgh, PA, USA). ADS and urease activities were normalized to protein content and defined as $\mu \mathrm{mol}$ ammonia liberated [minute $x$ (mg of protein) $]^{1}$.

In order to measure the amount of protein

Table 2- Summary of alcohol and sugary drinks consumption, and diet according to gender and socio-economic status (SES) $(n=52)$

\begin{tabular}{|c|c|c|c|c|c|c|c|}
\hline & Alcohol & $\begin{array}{l}\text { Sugary } \\
\text { drinks }\end{array}$ & Nuts & $\begin{array}{l}\text { Vegetables } \\
\text { and grains }\end{array}$ & $\begin{array}{c}\text { Dairy } \\
\text { products }\end{array}$ & Protein & $\begin{array}{c}\text { Total arginine } \\
\text { diet }\end{array}$ \\
\hline & $\begin{array}{c}\text { Mean } \\
\text { ounces/ day } \\
\text { (SD) }\end{array}$ & $\begin{array}{c}\text { Mean } \\
\text { ounces/day } \\
\text { (SD) }\end{array}$ & $\begin{array}{c}\text { Mean } \\
\text { number of } \\
\text { occasions/ } \\
\text { year (SD) }\end{array}$ & $\begin{array}{c}\text { Mean number } \\
\text { of occasions/ } \\
\text { year (SD) }\end{array}$ & $\begin{array}{c}\text { Mean } \\
\text { number of } \\
\text { occasions/ } \\
\text { year (SD) }\end{array}$ & $\begin{array}{c}\text { Mean } \\
\text { number of } \\
\text { occasions/ } \\
\text { year (SD) }\end{array}$ & $\begin{array}{c}\text { Mean number } \\
\text { of occasions/ } \\
\text { year (SD) }\end{array}$ \\
\hline \multicolumn{8}{|l|}{ Gender } \\
\hline Male & $1.0(1.4)^{*}$ & $2.1(3.1)$ & $97.2(96.5)$ & $899.5(479.6)$ & 498.2(373.9) & $583.6(711.3)$ & $2078.4(1348.3)$ \\
\hline Female & $0.2(0.5)$ & $0.6(0.9)$ & $156.8(241.3)$ & $1007.0(613.7)$ & $465.9(335.5)$ & $344.3(230.9)$ & $1974.0(613.7)$ \\
\hline \multicolumn{8}{|l|}{ SES } \\
\hline Lower & $0.8(1.0)$ & $3.7(4.0)^{*}$ & $90.5(2.1)$ & $1385.5(359.9)$ & $415.5(20.5)$ & $602.5(543.8)$ & $2494.0(881.1)$ \\
\hline Middle & $0.4(1.0)$ & $0.5(1.1)$ & $268.3(314.5)$ & $840.3(459.6)$ & $451.9(377.2)$ & $307.6(186.5)$ & $1868.1(1032.5)$ \\
\hline Upper & $0.3(0.9)$ & $0.8(1.1)$ & $84.7(116.2)$ & $982.1(610.7)$ & $493.8(354.5)$ & $466.4(546.4)$ & $2027.0(1236.5)$ \\
\hline
\end{tabular}

Table 3- Summary of mean alkali production\# and oral health index according gender and socio-economic status (SES) $(n=52)$

\begin{tabular}{cccccc}
\hline & $\begin{array}{c}\text { Arginine plaque } \\
\text { Mean(SD) }\end{array}$ & $\begin{array}{c}\text { Arginine saliva } \\
\text { Mean(SD) }\end{array}$ & $\begin{array}{c}\text { Urea } \\
\text { Mean(SD) }\end{array}$ & Mean(SD) & OHI \\
\hline Gender & & & & & \\
Male & $1.6(1.4)$ & $0.8(1.0)$ & $2.8(2.4)$ & $0.3(0.5)$ & $28.5(27.6)^{*}$ \\
\hline Female & $1.4(1.2)$ & $1.0(1.0)$ & $3.1(2.5)$ & $0.2(0.4)$ & $13.7(17.8)$ \\
\hline SES & & & & & \\
Lower & $0.6(0.3)^{*}$ & $0.1(0.1)^{*}$ & $1.2(1.1)^{*}$ & $0.1(0.2)$ & $40.4(39.0)$ \\
Middle & $1.3(1.1)$ & $0.1(0.1)$ & $3.8(2.4)$ & $0.4(0.5)$ & $17.5(23.6)$ \\
Upper & $1.8(1.4)$ & $1.0(1.0)$ & $3.0(2.6)$ & $0.2(0.4)$ & $13.6(11.0)$ \\
\hline
\end{tabular}

\# $\mathrm{mmol}$ ammonia liberated [minute $\mathrm{x}$ (mg of protein)]-1

${ }^{*} \mathrm{p}$-value $<0.05-\mathrm{OHI}=$ oral hygiene scores 
present in the samples, $200 \mu \mathrm{l}$ of the samples were mixed with $200 \mu \mathrm{l}$ of glass beads $(0.1-\mathrm{mm}$, BioSpec Products, Inc. Bartlesville, OK, USA) followed by homogenization in a Bead Beater using two cycles of $30 \mathrm{~s}$, with cooling on ice during the interval. The samples were then centrifuged for 5 min at $13,000 \mathrm{~g}$ in a refrigerated microcentrifuge (Labnet International, Woodbridge, NJ, USA). Protein concentration of the supernatant fluid was determined using Bradford method with the BioRad protein assay reagent (BioRad Laboratories, Hercules, CA, USA) using bovine serum albumin as the standard.

\section{Statistical analyses}

Data were examined for outliers and distributional form. Wilcoxon rank sum tests were used to compare two groups of ordinal data. Kruskal-Wallis tests were used to compare three or more groups of ordinal data. Spearman correlations were used to compute all associations. SAS Version 9.2 (Cary, N.C.) was used for all data analyses. Two-sided tests were conducted using a 0.05 level of significance.

\section{RESULTS}

The mean (SD) age of the 52 participants included in this report was 30.7 (10.9) years with a median age of 26 years, the sample is further described in Table 1 . Of these participants, $29 \%$

Table 4- Distribution of correlation coefficients for patient's characteristics and alkali production\#

\begin{tabular}{|c|c|c|c|c|}
\hline \multicolumn{5}{|c|}{ Spearman Correlation Coefficients } \\
\hline \multicolumn{5}{|c|}{ Prob $>|r|$ under HO: Rho=0 } \\
\hline \multicolumn{5}{|c|}{ Number of Observations } \\
\hline & Arginine plaque & Arginine saliva & Urea plaque & Urea saliva \\
\hline \multirow[t]{3}{*}{ Oral Hygiene Index } & -0.21042 & -0.30197 & -0.33556 & 0.10583 \\
\hline & 0.1343 & 0.0296 & 0.015 & 0.4553 \\
\hline & 52 & 52 & 52 & 52 \\
\hline \multirow{3}{*}{$\begin{array}{l}\text { Alcohol consumption/ } \\
\text { day }\end{array}$} & -0.02854 & -0.13485 & -0.01241 & 0.27408 \\
\hline & 0.8456 & 0.3556 & 0.9326 & 0.0567 \\
\hline & 49 & 49 & 49 & 49 \\
\hline \multirow{3}{*}{$\begin{array}{c}\text { Sugary drink } \\
\text { consumption/day }\end{array}$} & -0.17484 & -0.43634 & -0.28078 & -0.18328 \\
\hline & 0.2151 & $0.0012^{*}$ & $0.0438^{*}$ & 0.1934 \\
\hline & 52 & 52 & 52 & 52 \\
\hline \multirow[t]{3}{*}{ Tobacco use/day } & -0.35223 & -0.32256 & -0.46212 & 0.14209 \\
\hline & $0.0131^{*}$ & $0.0238^{*}$ & $0.0008^{*}$ & 0.3301 \\
\hline & 49 & 49 & 49 & 49 \\
\hline \multirow[t]{3}{*}{ Consumption of nuts } & -0.27179 & -0.28808 & -0.20338 & -0.01153 \\
\hline & 0.126 & 0.104 & 0.2563 & 0.9492 \\
\hline & 33 & 33 & 33 & 33 \\
\hline \multirow{3}{*}{$\begin{array}{c}\text { Consumption of } \\
\text { vegetables and grains }\end{array}$} & 0.18097 & -0.20992 & -0.0493 & -0.12613 \\
\hline & 0.3135 & 0.241 & 0.7853 & 0.4843 \\
\hline & 33 & 33 & 33 & 33 \\
\hline \multirow{3}{*}{$\begin{array}{l}\text { Consumption of dairy } \\
\text { products }\end{array}$} & 0.03889 & -0.10718 & 0.0729 & 0.11076 \\
\hline & 0.8299 & 0.5527 & 0.6868 & 0.5395 \\
\hline & 33 & 33 & 33 & 33 \\
\hline \multirow{3}{*}{$\begin{array}{l}\text { Consumption of } \\
\text { protein }\end{array}$} & 0.1727 & -0.16283 & 0.06869 & -0.09771 \\
\hline & 0.3365 & 0.3653 & 0.7041 & 0.5886 \\
\hline & 33 & 33 & 33 & 33 \\
\hline \multirow{3}{*}{$\begin{array}{c}\text { Total consumption of } \\
\text { arginine diet }\end{array}$} & 0.13592 & -0.2126 & -0.01838 & -0.08247 \\
\hline & 0.4507 & 0.2349 & 0.9191 & 0.6482 \\
\hline & 33 & 33 & 33 & 33 \\
\hline
\end{tabular}

$\# \mu$ mol ammonia liberated [minute $x(\mathrm{mg} \text { of protein) }]^{-1}$

*Significant relationship at $p=0.05$ 
consumed alcohol, $44 \%$ consumed sugary drinks, and $23 \%$ used tobacco. Dietary intake of arginine rich foods was available for 33 of the 52 participants.

To address the aim of this study, "the relationships among alkali production, diet, oral health behaviors, and oral hygiene", we first examined the relationship of age with oral health behaviors and diet. We found no significant associations between age and alcohol, sugary drinks, or tobacco use. There was a significant association between age and protein consumption $(r=-0.35, p<0.05)$ but not consumption of other foods. Older participants consumed less protein. Males consumed significantly more alcohol than females $(p<0.05)$, but no gender differences were found for sugary drink consumption, tobacco use,

Table 5- Distribution of correlation coefficients for patient's characteristics and oral hygiene index

\begin{tabular}{|c|c|}
\hline \multicolumn{2}{|c|}{ Spearman Correlation Coefficients } \\
\hline \multicolumn{2}{|c|}{ Prob $>|r|$ under H0: Rho=0 } \\
\hline \multicolumn{2}{|c|}{ Number of Observations } \\
\hline & $\mathrm{OHI}$ \\
\hline \multirow[t]{3}{*}{ Alcohol/day } & 0.34909 \\
\hline & $0.0140^{*}$ \\
\hline & 49 \\
\hline \multirow[t]{3}{*}{ Sugary drinks /day } & 0.41023 \\
\hline & $0.0025^{*}$ \\
\hline & 52 \\
\hline \multirow[t]{3}{*}{ Tobacco use/day } & 0.34523 \\
\hline & $0.0025^{*}$ \\
\hline & 49 \\
\hline \multirow[t]{3}{*}{ Consumption of nuts } & 0.06532 \\
\hline & 0.718 \\
\hline & 33 \\
\hline \multirow{3}{*}{$\begin{array}{c}\text { Consumption of } \\
\text { vegetables and grains }\end{array}$} & -0.30559 \\
\hline & 0.0837 \\
\hline & 33 \\
\hline \multirow{3}{*}{$\begin{array}{l}\text { Consumption of dairy } \\
\text { products }\end{array}$} & -0.38143 \\
\hline & $0.0285^{*}$ \\
\hline & 33 \\
\hline \multirow[t]{3}{*}{ Consumption of protein } & -0.13675 \\
\hline & 0.4479 \\
\hline & 33 \\
\hline \multirow{3}{*}{$\begin{array}{l}\text { Total consumption of } \\
\text { arginine diet }\end{array}$} & -0.35028 \\
\hline & $0.0457^{*}$ \\
\hline & 33 \\
\hline
\end{tabular}

*Significant relationship at $p=0.0$ or dietary intake. Participants in the lowest SES (Socio-economic status) group consumed sugary drinks the most $(p<0.01)$ and had the highest rate of tobacco use $(p<0.05)$. Subjects with a lower SES were also more likely to have higher frequency rate (amount per day) of sugary drink consumption. No significant differences were found on other dietary intake by SES group (Table 2).

We then examined the relationship between age, gender, SES, and alkali production. We found no significant relationship between age or gender and alkali production. There were significant differences among the SES groups for ADS activity in plaque $(p<0.05)$, ADS activity in saliva $(p<0.01)$, and urease activity in plaque $(p<0.05)$ as shown in Table 3.

Additionally, we computed the associations among oral health behaviors, including diet, and alkali production. The results in Table 4 show significant negative associations between alkali production and both sugary drink consumption [ADS activity saliva $(p<0.0012)$, urease activity in plaque $(p=<0.0438)]$ and tobacco use [ADS activity in plaque $(p=<0.0131)$, ADS activity in saliva $(p=<0.0238)$, urease activity in plaque $(p=<0.0008)]$. Higher rates of sugary drink consumption and tobacco use were significantly related to lower alkali production.

We also examined the relationship of the oral hygiene scores (OHI) with age, gender, SES, diet, alkali production, and oral health behaviors. There was a significant relationship between age, SES and OHI $(p<0.05)$. We also found a significant gender difference, with females having better (lower) OHI scores $(p<0.01)$. A significant relationship between $\mathrm{OHI}$ and alcohol consumption $(\mathrm{p}=<0.0140)$, sugary drinks consumption $(p=<0.0025)$, and tobacco use $(p=<0.0025)$ was also found. Those three behaviors variables resulted in poor (higher) $\mathrm{OHI}$ scores. We also found that patients who had a higher consumption of dairy products $(p=<0.0285)$ and total consumption of arginine rich foods $(p=<0.0457)$ presented with significantly better (lower) OHI scores (Table 5).

\section{SCUSSI ON}

The current paper was built from an original study where part of the data has been published elsewhere. We further explored the demographic data from two previous publications that revealed a positive relationship between high levels of alkali production and caries resistance, as significantly higher levels of urease and ADS activities were seen in individuals experiencing no caries activity, compared with individuals who had active caries ${ }^{11,21}$. The initial study also showed a significantly positive association between certain species of alkali 
producing bacteria and levels of ADS and urease activities $^{11,21}$. Other studies also suggested ${ }^{24}$ that caries-resistant individuals are more likely to have an alkaline plaque structure when compared to caries-susceptible individuals. Small differences in urea concentration and in the amount of urease enzyme may significantly affect the initiation and progress of dental caries. Therefore, it was clear that an increase in alkali production in the oral environment is desirable. The current study aimed to explore if certain patient's characteristics such as diet, oral health behaviors, and oral hygiene have any relationship with patient's alkali production.

The relationship between SES (socio-economical status) and oral health-related quality of life has been the subject of many studies, however little is known about socio-demographic factors and how they relate to both favorable and unfavorable oral health behaviors, including diet. Although tooth loss is declining in US adults, the need for various types of dental services in the adult population continues to increase ${ }^{23}$. In the current study, age seemed to be correlated with oral hygiene with older participants presenting poorer oral hygiene results. A previous study looking at the elderly population concluded that those with transportation difficulties, with income less than $\$ 16,000 /$ year, African Americans, and those with a $6^{\text {th }}$-grade education or less were more likely to report oral health-related quality of life decrements ${ }^{16}$. Although preventing oral disease in aged patients requires an understanding of the risk factors, research suggests that the disease in older adults is probably not due to greater risk but, the results of cumulative disease progression over time ${ }^{23}$. Other studies reporting the association between SES and children concluded that dental caries, obesity, and poorer cardiovascular health coexist in patients of low socioeconomic status ${ }^{18,25}$ with a three-fold increase in caries level in low versus high SES status. The results from the current study also revealed a significant association between lower SES and certain oral health related behaviors. Subjects with a lower SES were more likely to use tobacco, drink alcohol, and consume sugary drinks. Subjects with a lower SES were also more likely to have higher frequency rate of sugary drink consumption. Worse oral hygiene scores were also associated with alcohol use, sugary drinks and tobacco use. Similarly, studies have reported higher propensity of certain risk behavior factors such as tobacco use, alcohol use, and obesity in individuals with lower income, education, and employment status $^{18,25}$.

The study showed lower levels of alkali production for patients who self-reported higher frequency of use of sugary drinks. Additionally, increased consumption of sugary drinks was associated with poor oral hygiene. Numerous studies have shown that frequent consumption of a diet rich in sugar is significantly associated with an increase in dental caries risk ${ }^{20}$. There was a trend for male participants to consume more sugary drinks. Also, males who did drink sugary drinks consumed them at a higher frequency rate than females. A previous study looking at sugary beverage intake and obesity prevalence concluded that a positive association existed between high levels of sugary drink consumption among male students ${ }^{12}$. The current study also showed better oral hygiene scores for female patients, which is in line with the thinking that patients who are more likely to consume fewer sugary drinks may have better oral hygiene scores $^{30}$. Conversely, the current study showed that an increase in the intake of dairy-rich and argininerich foods were significantly related to better oral hygiene, which has also been suggested by results of previous studies ${ }^{2,15}$. The presence of arginine-rich proteins in the diet may provide a ready source of this amino acid ${ }^{2}$, which is the substrate for the arginine deiminase pathway that can provide an elevation of plaque $\mathrm{pH}$ values ${ }^{13}$. Proline can act as an acceptor for protons from lactate in the Stickland reaction ${ }^{4}$. This is a major but much-neglected metabolic pathway in dental plaque.

The results of the current study also showed a significant decrease in the intake of protein enriched foods with age. Ageing is associated with reduced food intake resulting in inadequate intakes in energy, and some nutrients ${ }^{31}$. The contribution of muscle protein to whole-body protein metabolism has been shown to be significantly reduced in the elderly ${ }^{19}$. A decrease in efficiency of protein utilization with aging may also call for a higher protein-intake recommendation ${ }^{19}$. An arginine-rich diet may act as a supplement to the body's natural ability to produce arginine ${ }^{29}$. In order to further understand the differences in the population's diet and how these differences relate to the SES of different aged adults, it is necessary to investigate why foods that are higher in protein may not be included often in the diets of subjects who were older. One reason may be that a growing number of elderly are either lactose intolerant or dislike dairy products ${ }^{31}$.

Tobacco use is a major risk factor in oral and systemic diseases ${ }^{1}$. In the current study, lower level of alkali production was seen in patients who self-reported higher frequency of use of tobacco products. Studies have confirmed that changes in micro-flora owing to tobacco use may play a role in the initiation and progression of dental caries ${ }^{3,21}$, which would explain some of the findings. The results of the current study also showed an association between increased use of tobacco and poor oral hygiene. In addition to the previously reported general health risks and periodontal disease related 
to tobacco use, the results of the current study provide a strong rationale for targeting smoking prevention and smoking cessation programs to tobacco users who have poor oral health behaviors and/or poor oral hygiene.

Increased consumption of alcohol was associated with poor oral hygiene. The study showed that male subjects drink more often and higher amounts of alcoholic beverages than female subjects. This data is consistent with the findings of the Center for Disease Control's Prevalence and Trends Data for Alcohol Consumption-20105. However, it seems that difference in alcohol use by gender seems to be becoming less evident ${ }^{2}$ depending on the investigation setting, public (public bar) versus private (at home). Understanding the trends found for alcohol consumption will help to specify the target population for oral health education. In addition, alcohol may act as both a promoter for tobacco and work as an independent risk factor for other diseases ${ }^{2}$.

Summarizing the relationships among alkali production, diet, oral health behaviors, and oral hygiene, we conclude that while no significant associations were found between age and alcohol, sugary drinks, or tobacco use, there was a significant relationship between age and protein consumption with older participants consuming less protein. The only significant gender differences found were for alcohol consumption and oral hygiene scores, with males consuming more alcohol than females, and females having better oral hygiene score than males. Participants in the lowest SES group consumed the highest amount of sugary drinks, had the highest rate of tobacco use, and lowest rate of alkali production in both plaque and saliva. We found no significant relationship between age or gender and alkali production. However, a significant negative association was found between alkali production in patients who consumed sugary drinks and used tobacco. A significant relationship was seen among certain demographic and behavioral variables and oral hygiene, with poor oral hygiene scores being observed in males, and in patients who consumed more alcohol and sugary drinks, and used tobacco products. Conversely, patients who consumed a higher percent of dairy products and arginine rich foods had significantly better oral hygiene scores.

\section{CONCLUSION}

The study showed a relationship between alkali production and oral hygiene, diet, and certain oral health behaviors. Patients who consumed high amount of sugary drinks and used tobacco had significantly lower levels of alkali production. Poor oral hygiene was significantly associated with age, lower SES, tobacco use, alcohol, and sugary drinks consumption.

\section{ACKNOWLEDGEMENTS}

This investigation was supported by NIH-NIDCR grant1R21 DE018392-01. Opinions and assertions contained herein are those of the authors and are not to be construed as necessarily representing the views of the respective organizations or the National Institutes of Health. The informed consent of all human subjects who participated in this investigation was obtained after the nature of the procedures had been explained fully.

\section{CONFLI CT OF | NTEREST}

The authors declare that they have no conflict of interest.

\section{REFERENCES}

1- Bergström J, Eliasson S, Dock J. Exposure to tobacco smoking and periodontal health. J Clin Periodontol. 2000;27(1):61-8.

2- Bond JC, Roberts SC, Greenfield TK, Korcha R, Ye Y, Nayak MB. Gender differences in public and private drinking contexts: a multi-level GENACIS analysis. Int J Environ Res Public Health. 2010;7:2136-60.

3- Boström L, Linder L, Bergström J. Smoking and cervicular fluid levels of IL-6 and TNF-alpha in periodontal disease. J Clin Periodontol. 1999;26:352-7.

4- Bowen W. Food components and caries. Adv Dental Res. 1994;8:215-20.

5- Centers for Disease Control and Prevention. Prevalence and trends data for alcohol consumption - 2010 [online]. 2010. [cited June 10, 2014]. Available from: http://apps.nccd.cdc.gov/brfss/ list. asp?cat $=A C \& y r=2010 \& q k e y=4413 \&$ state $=$ All.

6- Clancy A, Burne RA. Construction and characterization of a recombinant ureolytic Streptococcus mutans and its use to demonstrate the relationship of urease activity to $\mathrm{pH}$ modulating capacity. FEMS Microbiol Lett. 1997;151:205-11.

7- Coleman R. The continuing significance of social class in marketing. J Cons Res. 1983;10:265-80.

8- Denepitiya L, Kleinberg I. A comparison of the microbial compositions of pooled human dental plaque and salivary sediment. Arch Oral Biol. 1982;27:739-45.

9- Ekstrand KR, Ricketts DN, Kidd EA. Reproducibility and accuracy of three methods for assessment of demineralization depth on the occlusal surface: an in vitro examination. Caries Res. 1997;31:224-31.

10- Gibson S, Williams S. Dental caries in pre-school children: associations with social class, toothbrushing habit and consumption of sugars and sugar-containing foods. Further analysis of data ftom the National Diet and Nutrition Survey of children aged 1.5-4.5 years. Caries Res. 1999;33:101-13.

11- Gordan VV, Garvan CW, Ottenga ME, Schulte R, Harris PA, McEdward D, et al. Could alkali production be considered an approach for caries control? Caries Res. 2010;44:547-54.

12- Jia M, Wang C, Zhang Y, Zheng Y, Zhang L, Huang Y, et al. Sugary beverage intakes and obesity prevalence among junior high school students in Beijing - a cross-sectional research on SSBs intake. Asia Pac J Clin Nutr. 2012;21:425-30.

13- Kleinberg I. Effect of urea concentrations on plaque $\mathrm{pH}$ in vivo. Journal of Dental Research. 1961;40:751-752. 
14- Kleinberg I. A mixed-bacteria ecological approach to understanding the role of the oral bacteria in dental caries causation: an alternative to Streptococcus mutans and the specificplaque hypothesis. Crit Rev Oral Biol Med. 2002;13:108-25.

15- Llena C, Forner L. Dietary habits in a child population in relation to caries experience. Caries Res. 2008;42:387-93.

16- Makhija SK, Gilbert GH, Boykin MJ, Litaker MS, Allman RM, Baker PS, et al. The relationship between sociodemographic factors and oral health - related quality of life in dentate and edentulous community-dwelling older adults. J Am Geriatr Soc. 2006;54:1701-12.

17- Margolis HC, Duckworth JH, Moreno EC. Composition of pooled resting plaque fluid from caries-free and caries-susceptible individuals. J Dent Res. 1988;67:1468-75.

18- Marshall TA, Eichenberger-Gilmore JM, Broffitt BA, Warren J], Levy SM. Dental caries and childhood obesity: roles of diet and socioeconomic status. Community Dent Oral Epidemiol. 2007;35:449-58.

19- Morais J, Chevalier S, Gougeon R. Protein turnover and requirements in the healthy and frail elderly. J Nutr Health Aging. 2005; 10:272-83.

20- Moynihan P, Petersen PE. Diet, nutrition and the prevention of dental diseases. Public Health Nutr. 2004;7:201-26.

21- Nascimento MM, Gordan VV, Garvan CW, Browngardt CM, Burne RA. Correlations of oral bacterial arginine and urea catabolism with caries experience. Oral Microbiol Immunol. 2009;24:89-95.

22- Nauntofte B, Tenovuo J, Lagerlof F, Fejerskov O, Kidd E. Secretion and composition of saliva. In: Fekerskov O, Kidd E, editors. Dental caries: the disease and its clinical management. $1^{\text {st }}$ ed. Oxford: Blackwell Munksgaard; 2003.
23- Niessen LC, Fedele DJ. Aging successfully: oral health for the prime of life. Compend Contin Educ Dent. 2002;23:4-11.

24- O'Leary TJ, Drake RB, Naylor JE. The plaque control record. J Periodontol. 1972;43:38.

25- Poulton R, Caspi A, Milne BJ, Thomson WM, Taylor A, Sears MR, et al. Association between children's experience of socioeconomic disadvantage and adult health: a life-course study. Lancet. 2002;360:1640-5.

26- Sakamaki ST, Bahn AN. Effect of orthodontic banding on localized oral lactobacilli. J Dent Res. 1968;47:275-9.

27- United States Department of Health and Human Services. Oral health in America: a report of the Surgeon General. Rockville: Department of Health and Human Services; 2000.

28- Van Wuyckhuyse BC, Perinpanayagam HE, Bevacqua D, Raubertas RF, Billings RJ, Bowen WH, et al. Associations of free arginine and lysine concentrations in human parotid saliva with caries experience. J Dent Res. 1995;74:686-90.

29- Wells BJ, Mainous AG 3rd, Everett CJ. Association between dietary arginine and C-reactive protein. Nutrition. 2005;21:12530.

30- Wickholm S, Söder PO, Galanti MR, Söder B, Klinge B. Periodontal disease in a group of Swedish adults snuff and cigarette users. Acta Odontol Scand. 2004;62:333-8.

31- Zhu K, Devine A, Suleska A, Tan CY, Toh CZ, Kerr D, et al. Adequacy and change in nutrient and food intakes with aging in a seven-year cohort study in elderly women. J Nutr Health Aging. 2010;14:723-9. 